\title{
Eligibility for Statin Therapy by the JUPITER Trial Criteria and Subsequent Mortality (From the REGARDS Cohort)
}

\author{
Mary Cushman, MD, MSc ${ }^{a, b}$, Leslie A. McClure, PhDC , Susan G. Lakoski, MD, MS ${ }^{d}$, and Nancy \\ S. Jenny, PhDb \\ aDepartment of Medicine, University of Vermont, Burlington, VT \\ bDepartment of Pathology, University of Vermont, Burlington, VT \\ 'Department of Biostatistics, University of Alabama at Birmingham, Birmingham, AL \\ dDepartment of Internal Medicine, University of Texas Southwestern Medical Center, Dallas, TX
}

\begin{abstract}
The Justification of the Use of Statins in Primary Prevention: an Intervention Trial Using Rosuvastatin (JUPITER) reported reduced cardiovascular and all-cause mortality with statin treatment in patients with elevated C-reactive protein (CRP) and average cholesterol, who were not eligible for lipid-lowering treatment based on existing guidelines. We determined the prevalence of eligibility and mortality in a general population sample based on eligibility for statin treatment using JUPITER criteria. We studied 30,229 participants of the $\underline{\text { RE} a s o n s ~ f o r ~ G e o g r a p h i c ~} \underline{\text { And }}$ Racial Differences in $\underline{S}$ troke (REGARDS) cohort, an observational study of US African-American and white participants aged 45 and older, enrolled in their homes between 2003-2007, and followed biannually by telephone. Among 11,339 participants age-eligible for JUPITER and without a vascular diagnosis or using lipid-lowering treatment, $21 \%(2,342)$ met JUPITER entry criteria. Compared to JUPITER participants, they had similar LDL cholesterol and CRP, were more often women, black, had metabolic syndrome and used aspirin for cardioprotection. Over 3.5 years follow-up, the mortality rate among REGARDS participants eligible for JUPITER was 1.17 per 100 person-years $(95 \%$ CI 0.94-1.42). Compared to those otherwise JUPITER eligible who had CRP $<2 \mathrm{mg} / \mathrm{L}(\mathrm{n}=2,620)$, those with CRP $\geq 2 \mathrm{mg} / \mathrm{L}$ had a multivariable-adjusted relative risk of 1.5 (95\% CI, 1.1-2.2) for total mortality. In conclusion, $21 \%$ not otherwise eligible would be newly eligible for lipid-lowering treatment based on JUPITER trial eligibility.
\end{abstract}

\section{Keywords}

cardiovascular risk factors; mortality; statin; C-reactive protein

The Justification of the Use of Statins in Primary Prevention: an Intervention Trial Using Rosuvastatin (JUPITER), reported that non-diabetics who were not eligible for lipid-lowering treatment and who had C-reactive protein (CRP) $\geq 2.0 \mathrm{mg} / \mathrm{L}$, had a $44 \%$ reduction of vascular events and cardiovascular mortality, and $20 \%$ reduction in all cause mortality with rosuvastatin

\footnotetext{
(c) 2009 Excerpta Medica, Inc. Published by Elsevier Inc. All rights reserved.

Correspondence and reprints: Mary Cushman, MD, MSc, University of Vermont, 208 South Park, Drive, Colchester, VT 05446. phone: 802-656-8968. fax: 802-656-8965. mary.cushman@uvm.edu.

Publisher's Disclaimer: This is a PDF file of an unedited manuscript that has been accepted for publication. As a service to our customers we are providing this early version of the manuscript. The manuscript will undergo copyediting, typesetting, and review of the resulting proof before it is published in its final citable form. Please note that during the production process errors may be discovered which could affect the content, and all legal disclaimers that apply to the journal pertain.
} 
treatment compared to placebo ${ }^{1}$. If these findings are translated to practice, current guidelines for statin use in primary prevention may change dramatically, leading to increased use of this treatment. We recently reported a high prevalence of elevated CRP in a biracial national U.S.

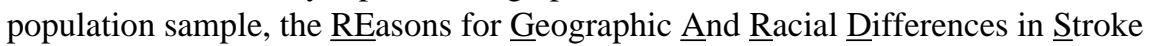

(REGARDS) cohort (Cushman et al., In press). Among these black and white adults without cardiovascular disease, $40 \%$ had elevated CRP; this percentage was higher in women than men and in blacks than whites. Here, we evaluated the potential impact of JUPITER on lipid lowering prescription in U.S. blacks and whites by assessing the prevalence of eligibility for JUPITER among REGARDS participants. To address the potential impact of aggressive lipid lowering, we determined mortality rates of JUPITER eligible participants with and without $\mathrm{CRP} \geq 2 \mathrm{mg} / \mathrm{L}$.

\section{Methods}

The REGARDS study is a national population-based cohort study in the United States. Between February 2003 and October, 2007, 30,229 individuals over age 45 were enrolled, targeted for equal representation of whites and blacks, and men and women ${ }^{2}$. Fifty-six percent of the sample resided in the 10 southeastern stroke belt states, with the rest from the other 40 contiguous states. Individuals were recruited from a commercial list representing most of the population using mail and telephone contact. Exclusion criteria were race other than black or white (race was self-defined by participants who chose from a list), active cancer treatment, medical conditions preventing long-term participation, cognitive impairment, inability to communicate in English and residence in, or on a waiting list for a nursing home. Race was assessed as the parent study aims to investigate black-white disparities in vascular disease. For consenting participants, demographic information and medical history were obtained using a computer-assisted telephone interview. Following this, during an in-home examination blood pressure, anthropomorphic measures, electrocardiogram, and a medication inventory were assessed, and blood drawn, using standardized protocols. Self-administered questionnaires were left with each participant to assess family history of stroke and heart disease. Participants are followed by telephone at six-month intervals for surveillance of medical events, including death. For reported deaths, death certificates were sought and medical records from hospitalizations temporally related to the death were retrieved to confirm death and date of death. Study procedures were reviewed and approved by the Institutional Review Boards at each study institution.

Phlebotomy was performed by centrally trained personnel using standardized procedures in each participant's home after a 10-12 hour fast. Samples were centrifuged and serum or plasma separated and shipped overnight on gel ice packs to the University of Vermont. On arrival, samples were re-centrifuged at $30,000 \mathrm{xG}$ and $4^{\circ}$ Celsius, and either analyzed or aliquoted for storage at $-80^{\circ}$ Celsius.

CRP was analyzed in periodic batches by particle enhanced immunonephelometry using the BNII nephelometer (N High Sensitivity CRP; Dade Behring Inc., Deerfield, IL) with analytical interassay coefficients of variation of 2.1-5.7\%. Cholesterol, high-density lipoprotein (HDL) cholesterol, triglycerides, creatinine and glucose were measured by colorimetric reflectance spectrophotometry using the Ortho Vitros Clinical Chemistry System 950IRC instrument (Johnson \& Johnson Clinical Diagnostics, Rochester, NY), with LDL cholesterol calculated by the Friedwald equation. Estimated glomerular filtration rate was calculated by the abbreviated Modification of Diet in Renal Disease equation after calibration of creatinine values ${ }^{3}$.

We applied JUPITER entry criteria to determine the proportion of REGARDS participants that would have been eligible for the trial ${ }^{4}$. Of 30,229 participants, we excluded 581 men $<50$ and 
5,671 women <60 years of age. Secondly, 7,999 (30\%) reporting a vascular diagnosis at baseline (myocardial infarction, stroke, peripheral arterial disease, transient ischemic attack, carotid endarterectomy, peripheral artery bypass surgery or angioplasty, leg amputation, coronary artery angioplasty or stenting) and 4,639 taking lipid lowering medications (fibrates, niacin, bile-acid sequestrants or statins) were excluded. This resulted in a cohort of 11,339 participants who were evaluated further for JUPITER entry criteria. We considered the major entry criteria of LDL cholesterol $<130 \mathrm{mg} / \mathrm{dl}$, no diabetes, no current use of hormone replacement therapy, creatinine $\leq 2.0 \mathrm{mg} / \mathrm{dL}$ and triglycerides $<500 \mathrm{mg} / \mathrm{dL}$. We excluded 645 participants with missing LDL cholesterol or diabetes status. For participants whose LDL could not be calculated due to triglycerides $>400 \mathrm{mg} / \mathrm{dL}$, we assumed LDL was $>130 \mathrm{mg} / \mathrm{dL}$.

REGARDs did not collect specific data on some JUPITER entry criteria: past lipid lowering use, cancer within the past 5 years, elevated alanine aminotransferase or creatine kinase, recent alcohol or drug abuse, uncontrolled hypothyroidism, severe arthritis, lupus, inflammatory bowel disease, and taking cyclosporine, tacrolimus, azathioprine or chronic glucocorticoids.

We defined risk factors using the same definitions as the JUPITER investigators whenever possible. Diabetes mellitus was defined by self-reported physician diagnosis with use of antidiabetic medications, fasting glucose $\geq 126 \mathrm{mg} / \mathrm{dl}$ or non-fasting glucose $>200 \mathrm{mg} / \mathrm{dl}$. Cigarette smoking was categorized as current smoking or nonsmoking. Metabolic syndrome was defined according to American Heart Association and National Heart, Lung, and Blood Institute 2005 guidelines ${ }^{5}$. Family history of coronary heart disease was defined as diagnosis in a parent or sibling prior to age 60 years.

The Framingham 10-year heart disease risk score ${ }^{6}$ and the Reynolds Risk Score ${ }^{1,7}$, which includes parental history of myocardial infarction and CRP concentration, were calculated.

SAS version 9.1 (Cary, NC) was used for analysis. The numbers of REGARDS participants with each JUPITER exclusion criteria were tallied to yield a flow chart of eligibility. Prevalence of $\mathrm{CRP} \geq 2 \mathrm{mg} / \mathrm{L}$ was determined and baseline characteristics by CRP category were compared using t-tests, ANOVA, or chi-square tests. Characteristics of those with elevated CRP were compared descriptively to published characteristics of JUPITER participants ${ }^{1}$. We compared the number eligible for statin treatment based on JUPITER criteria (eligible and CRP $\geq 2 \mathrm{mg}$ / L) to the number eligible by ATPIII guidelines 8 .

We constructed Kaplan-Meier plots and used log rank tests to compare incidence of all-cause mortality in those with $\mathrm{CRP} \geq 2 \mathrm{mg} / \mathrm{L}$ compared to $<2 \mathrm{mg} / \mathrm{L}$. Cox proportional hazards models were used to calculate the hazard ratio, an estimate of relative risk, of all-cause death by CRP category in a crude model, a model adjusting for age, race and sex, a model further adjusting for hypertension, smoking status, education level, body-mass index, lipid and glucose levels, estimated glomerular filtration rate, and a model including all previously listed factors and metabolic syndrome. We censored individuals at death or last contact.

\section{Results}

There were 11,339 participants who were age-eligible for JUPITER and did not report baseline cardiovascular disease. This population is referred to hereafter as the "base population." From the base population, Figure 1 shows the number of REGARDS subjects who would have been eligible for the JUPITER trial based on other entry criteria. The most common reason for exclusion was LDL cholesterol $\geq 130 \mathrm{mg} / \mathrm{dL}$, followed by presence of diabetes. Among 4,910 participants who would be eligible for JUPITER based on standard risk factors up to the time of CRP testing, $52 \%$ had CRP $<2 \mathrm{mg} / \mathrm{L}$ and the remaining $48 \%$ had CRP $\geq 2 \mathrm{mg} / \mathrm{L}$, so would have been eligible for the trial. Thus, $21 \%$ would be newly eligible for use of rosuvastatin for 
primary prevention. Considering only non-diabetics, this percentage was $25 \%(2,342 /$ (11,399-1688 with diabetes-393 missing diabetes status)).

We applied ATPIII guidelines for lipid lowering using the Framingham Risk Score to define 10 -year risk of cardiovascular disease among nondiabetics in the base population $(n=9,258)$. There were 634 participants with a 10-year predicted risk $>20 \%$ and LDL cholesterol $\geq 130$ $\mathrm{mg} / \mathrm{dL} ; 376$ had 10-year risk 10-20\% with LDL cholesterol $\geq 160 \mathrm{mg} / \mathrm{dL}$ and 95 had 10-year predicted risk $<10 \%$ with $\mathrm{LDL} \geq 190 \mathrm{mg} / \mathrm{dL}$. Thus, $1,105(634+376+95)$, or $12 \%$ would be newly eligible for lipid-lowering treatment using these criteria.

In table 1, compared to those ineligible, those eligible for JUPITER based on elevated CRP were slightly older, more often female, black and had lower education level. They had higher levels of all risk factors except total and LDL cholesterol, diastolic blood pressure, estimated glomerular filtration rate and family history of coronary heart disease. The Framingham and Reynolds Risks Scores were also higher. They did not differ in frequency of aspirin use. In comparison to the published characteristics of JUPITER participants, REGARDS participants eligible for JUPITER were 0.8 years older, were much more often women or black and were more highly educated. The body-mass index was $0.4 \mathrm{~kg} / \mathrm{m}^{2}$ higher, glomerular filtration rate was $12 \mathrm{ml} / \mathrm{min} / 1.73 \mathrm{~m}^{2}$ lower and metabolic syndrome was more prevalent, while blood pressure and triglycerides were lower and glucose, CRP, LDL and HDL cholesterol were similar. Aspirin use was more than twice as prevalent in REGARDS participants, who also had a similar prevalence of a family history of heart disease and current smoking.

Figure 2 show Kaplan-Meier plots for all-cause mortality. Sixty-two (2\%) of those with CRP $<2 \mathrm{mg} / \mathrm{L}$ and $89(4 \%)$ with CRP $>2 \mathrm{mg} / \mathrm{L}$ died over a median follow up of 3.5 years (interquartile range 2.5-4.5). The annual incidence of mortality with $\mathrm{CRP} \geq 2 \mathrm{mg} / \mathrm{L}$ was $1.17 / 100$ personyears (95\% CI 0.94-1.42) and was $0.75 / 100$ person-years (95\% CI 0.57-0.94) with CRP <2 $\mathrm{mg} / \mathrm{L}$. Corresponding rates in women were 0.86 (95\% CI $0.58-1.20)$ and 0.55 (95\% CI 0.300.87 ), and for men 1.40 (95\% CI 1.07-1.78) and 0.83 (95\% CI 0.62-1.08). Corresponding rates for whites were $1.06(0.78-1.38)$ and 0.67 (95\% CI $0.47-0.89)$ and for blacks were 1.31 (95\% CI 0.94-1.75) and 0.93 (95\% CI 0.59-1.35).

Table 2 shows the relative risk of mortality for those with CRP $\geq 2.0 \mathrm{mg} / \mathrm{L}$, compared to those with lower levels. Regardless of the covariates included in the models, those with CRP $\geq 2 \mathrm{mg} /$ $\mathrm{L}$ were about $50 \%$ more likely to die during follow up. For participants with LDL below the median value (106 mg/dL) the adjusted hazard ratio of death was 1.51 (95\% CI 0.93-2.47) while for those with LDL above the median, the hazard ratio was 1.77 (95\% CI 0.96-3.25).

Among the 1,105 participants eligible for lipid-lowering treatment by the ATPIII criteria, the annual mortality incidence was 1.51 (95\% CI 1.14-1.94). Among these participants 618 (57\%) had CRP $\geq 2 \mathrm{mg} / \mathrm{L}$. Compared to those with CRP $<2 \mathrm{mg} / \mathrm{L}$, these participants had a 3.85 -fold higher risk of death (95\% CI 1.75-8.45), adjusted for other risk factors.

\section{Discussion}

Application of the JUPITER entry criteria to this general population sample revealed that among age-eligible people without cardiovascular disease or diabetes who were not taking lipid-lowering medications, $21 \%$ of participants would be newly eligible for statin treatment to prevent first cardiovascular events and reduce total mortality. This compares to eligibility of $12 \%$ applying the ATPIII criteria without CRP testing. Almost half of REGARDS participants eligible for JUPITER on the basis of clinical factors prior to CRP testing were eligible based on having a CRP $\geq 2 \mathrm{mg} / \mathrm{L}$. JUPITER-eligible REGARDS participants had more favorable levels of some risk factors and more adverse levels of others, compared to those enrolled in JUPITER, while the REGARDS participants were much more often women and 
black, and were more highly educated, than the trial participants. Among REGARDS participants eligible for JUPITER to the point of CRP testing, mortality was 50\% higher among those with $\mathrm{CRP} \geq 2 \mathrm{mg} / \mathrm{L}$ compared to those with CRP $<2 \mathrm{mg} / \mathrm{L}$.

The prevalence of eligibility for JUPITER in this study is higher than the $19 \%$ rate in a recent report of data from 2,322 participants of the National Health and Nutrition Examination Survey (NHANES) 1999-2004 survey ${ }^{9}$. This NHANES analysis was based on a smaller sample size than the current report and applied the JUPITER eligibility criteria differently, so results cannot be directly compared to the current report. A unique aspect of the current report is the inclusion of mortality data to assess the impact of JUPITER eligibility on health and to provide comparison data for mortality rates in JUPITER participants.

The clinical characteristics of REGARDS participants eligible for JUPITER differed from the trial participants on a few important factors, but despite this the mortality rate of these participants was similar to the JUPITER placebo group: 1.17/100 person-years compared to $1.25 / 100$ person-years ${ }^{1}$. If we extrapolate the hazard ratio of death with rosuvastatin from JUPITER, 0.80 (95\% CI .67-.97), we would anticipate a $20 \%$ reduction in mortality in this REGARDS population if rosuvastatin were prescribed to all eligible persons. This would lead to a mortality incidence of $0.94 / 100$ person-years; thus, we would expect 2.3 fewer deaths annually per 1000 treated.

Fewer REGARDS participants were eligible for lipid-lowering therapy applying the ATPIIII criteria compared to the JUPITER criteria, however these individuals had a higher mortality rate, 1.51 (95\% CI 1.14-1.94), than those eligible by JUPITER criteria. Thus, they might derive more individual benefit from statin treatment.

Limitations of our analysis need to be considered. We did not assess cardiovascular outcomes as they are not yet available for analysis in the REGARDS study. We did not have all JUPITER entry criteria defined in REGARDS participants, however those with active cancer and advanced medical conditions were excluded from REGARDS, so it is likely our exclusion criteria covered many of the same domains as JUPITER. Further, other JUPITER exclusion criteria are rare. REGARDS only measured CRP once, not twice, as JUPITER did.

Strengths of our study should be considered. REGARDS is a large population sample of black and white men and women recruited from across the continental United States. We used careful ascertainment of risk factors, many of which were measured rather than self-reported. Follow up was complete through 3.5 years, with a large number of deaths. Finally, REGARDS participants were recruited in similar years as JUPITER (February 2003 to December 2006).

In this general population sample considering non-diabetics, twice as many people would be eligible for lipid-lowering treatment if the JUPITER criteria were applied rather than ATPIII. Despite a different risk factor profile, the mortality rate in REGARDS participants eligible for JUPITER was similar to that in JUPITER participants randomized to placebo, supporting generalizability of the clinical trial population.

\section{Acknowledgments}

This project is supported by a cooperative agreement U01 NS041588 from the National Institute of Neurological Disorders and Stroke, National Institutes of Health, Department of Health and Human Services. The content is solely the responsibility of the authors and does not necessarily represent the official views of the National Institute of Neurological Disorders and Stroke or the National Institutes of Health. The authors acknowledge the participating investigators and institutions for their valuable contributions: The University of Alabama at Birmingham, Birmingham, Alabama (Study PI, Statistical and Data Coordinating Center, Survey Research Unit): George Howard DrPH, Virginia Howard PhD, Libby Wagner MA, Virginia Wadley PhD, Rodney Go PhD, Monika Safford MD, Ella Temple PhD, Margaret Stewart MSPH, J. David Rhodes BSN; University of Vermont (Central Laboratory): Rebekah Boyle, Elaine 
Cornell; Wake Forest University (ECG Reading Center): Ronald Prineas MD, PhD; Alabama Neurological Institute (Stroke Validation Center, Medical Monitoring): Camilo Gomez MD, Susana Bowling MD; University of Arkansas for Medical Sciences (Survey Methodology): LeaVonne Pulley PhD; University of Cincinnati (Clinical Neuroepidemiology): Brett Kissela MD, Dawn Kleindorfer MD; Examination Management Services, Incorporated (In-Person Visits): Andra Graham; Medical University of South Carolina (Migration Analysis Center): Daniel Lackland DrPH; Indiana University School of Medicine (Neuropsychology Center): Frederick Unverzagt PhD; National Institute of Neurological Disorders and Stroke, National Institutes of Health (funding agency): Claudia Moy $\mathrm{PhD}$.

\section{References}

1. Ridker PM, Danielson E, Fonseca FA, Genest J, Gotto AM Jr, Kastelein JJ, Koenig W, Libby P, Lorenzatti AJ, MacFadyen JG, Nordestgaard BG, Shepherd J, Willerson JT, Glynn RJ. Rosuvastatin to prevent vascular events in men and women with elevated C-reactive protein. $\mathrm{N}$ Engl J Med 2008;359:2195-2207. [PubMed: 18997196]

2. Howard VJ, Cushman M, Pulley L, Gomez CR, Go RC, Prineas RJ, Graham A, Moy CS, Howard G. The REasons for Geographic And Racial Differences in Stroke Study: objectives and design. Neuroepidemiology 2005;25:135-143. [PubMed: 15990444]

3. McClellan WM, Newsome BB, McClure LA, Cushman M, Howard G, Audhya P, Abramson JL, Warnock DG. Chronic kidney disease is often unrecognized among patients with coronary heart disease: The REGARDS Cohort Study. Am J Nephrol 2009;29:10-17. [PubMed: 18663284]

4. Ridker PM. Rosuvastatin in the primary prevention of cardiovascular disease among patients with low levels of low-density lipoprotein cholesterol and elevated high-sensitivity C-reactive protein: rationale and design of the JUPITER trial. Circulation 2003;108:2292-2297. [PubMed: 14609996]

5. Grundy SM, Cleeman JI, Daniels SR, Donato KA, Eckel RH, Franklin BA, Gordon DJ, Krauss RM, Savage PJ, Smith SC Jr, Spertus JA, Costa F. Diagnosis and management of the metabolic syndrome: an American Heart Association/National Heart, Lung, and Blood Institute scientific statement. Curr Opin Cardiol 2006;21:1-6. [PubMed: 16355022]

6. Wilson PW, D'Agostino RB, Levy D, Belanger AM, Silbershatz H, Kannel WB. Prediction of coronary heart disease using risk factor categories. Circulation 1998;97:1837-1847. [PubMed: 9603539]

7. Ridker PM, Buring JE, Rifai N, Cook NR. Development and validation of improved algorithms for the assessment of global cardiovascular risk in women: the Reynolds Risk Score. JAMA 2007;297:611-619. [PubMed: 17299196]

8. Executive Summary of The Third Report of The National Cholesterol Education Program (NCEP) Expert Panel on Detection, Evaluation, And Treatment of High Blood Cholesterol In Adults (Adult Treatment Panel III). JAMA 2001;285:2486-2497. [PubMed: 11368702]

9. Spatz ES, Canavan ME, Desai MM. From here to JUPITER: identifying new patients for statin therapy using data from the 1999-2004 National Health and Nutrition Examination Survey. Circ Qual Outcomes 2009;2:41-48. 


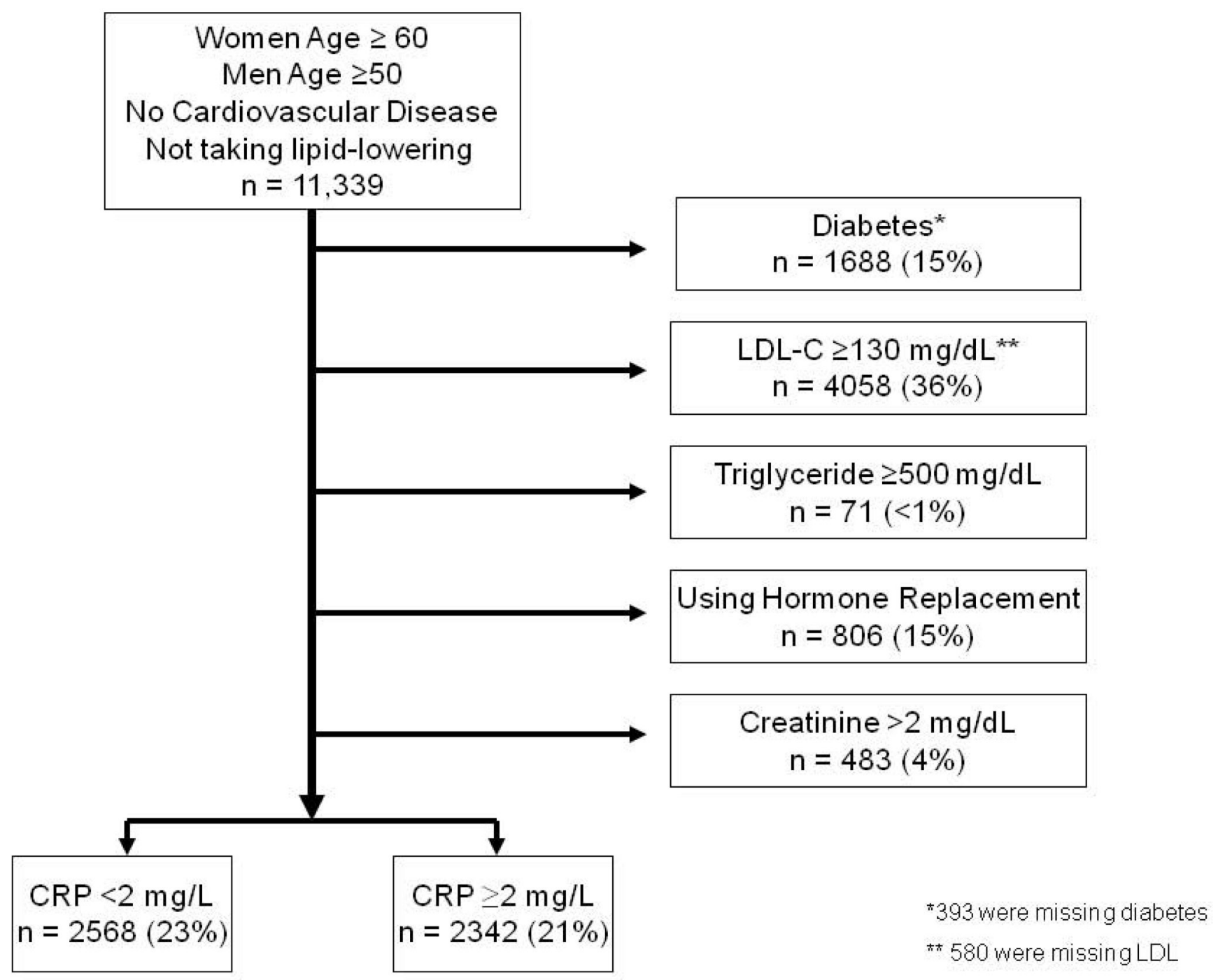

Figure 1.

Application of JUPITER eligibility criteria to the REGARDS population free of cardiovascular disease. $\mathrm{CRP}=\mathrm{C}$-reactive protein, $\mathrm{LDL}-\mathrm{C}=$ low density lipoprotein cholesterol 


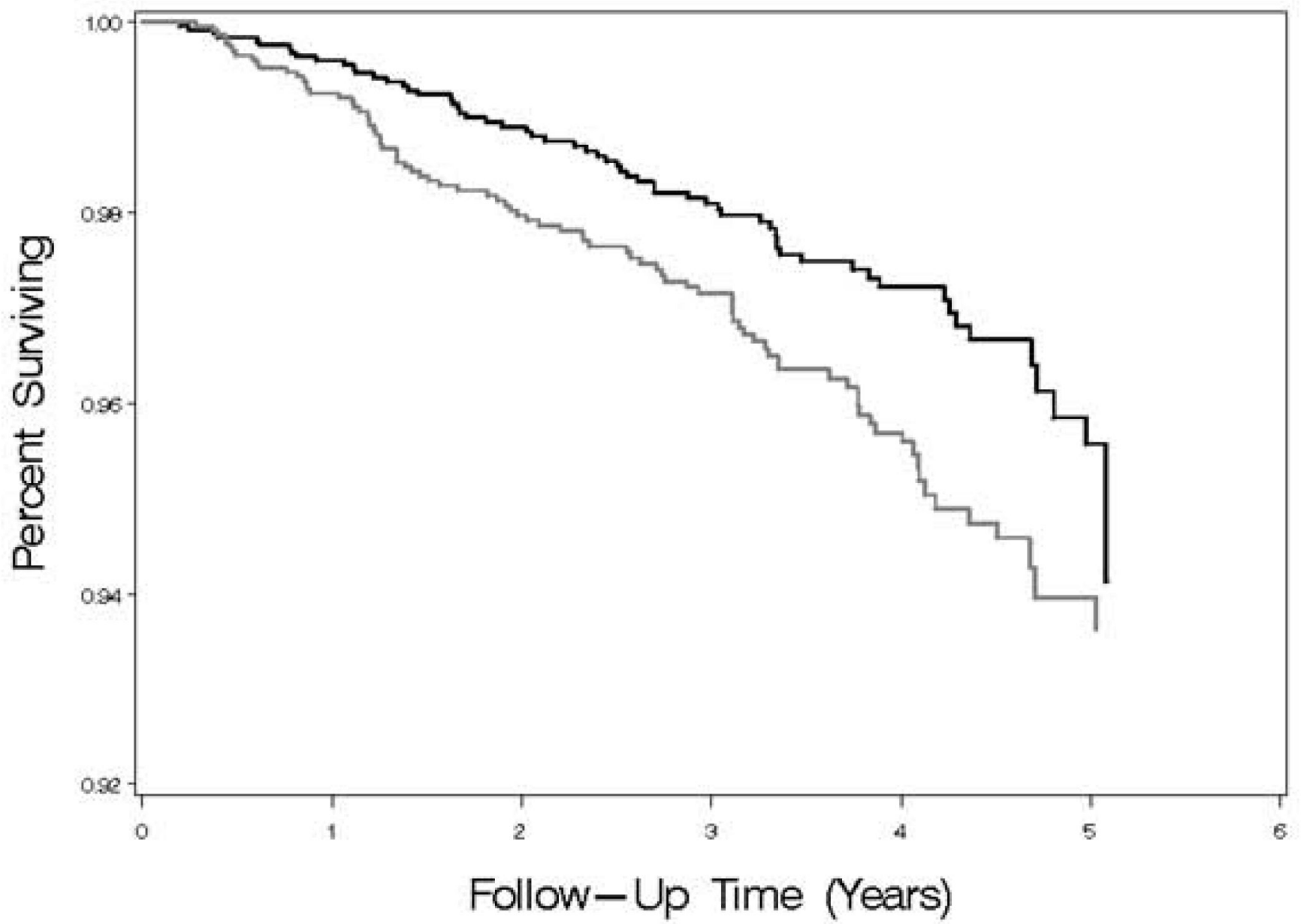

Figure 2.

Kaplan-Meier plot for all-cause mortality by CRP category for those meeting JUPITER entry criteria up to the time of CRP testing. Black line represents those with CRP $<2 \mathrm{mg} / \mathrm{L}$. Grey line represents those with $\mathrm{CRP} \geq 2 \mathrm{mg} / \mathrm{L}$. 
Table 1

Baseline Characteristics by C-reactive Protein Category, and Published Justification of the Use of Statins in Primary Prevention: an Intervention Trial Using Rosuvastatin (JUPITER) Participant Characteristics

\begin{tabular}{|c|c|c|c|c|}
\hline \multirow[t]{3}{*}{ Baseline Characteristic ${ }^{*}$} & \multicolumn{2}{|c|}{ C-reactive Protein (mg/L) } & \multirow[t]{3}{*}{ P-value ${ }^{\dagger}$} & \multirow{3}{*}{$\begin{array}{l}\text { JUPITER } \\
\text { Participants }^{\dagger}\end{array}$} \\
\hline & & & & \\
\hline & $(\mathrm{n}=2568)$ & $(\mathrm{n}=\mathbf{2 3 4 2})$ & & \\
\hline Age (years) & $66.4(60.7-73.3)$ & $67.1(61.9-73.3)$ & $<0.001$ & $66.3(60.9-71.8)$ \\
\hline Female & $848(33 \%)$ & $1086(46 \%)$ & $<0.001$ & $38.2 \%$ \\
\hline Black Race & $802(31 \%)$ & $981(42 \%)$ & $<0.001$ & $12.5 \%$ \\
\hline Education & & & $<0.001$ & \\
\hline HS Degree & $744(30 \%)$ & $906(39 \%)$ & & $59 \%$ \\
\hline Some College & $640(25 \%)$ & $669(29 \%)$ & & $18 \%$ \\
\hline College Degree & $628(24 \%)$ & $405(17 \%)$ & & $15 \%$ \\
\hline Post Graduate & $555(22 \%)$ & $362(15 \%)$ & & $8 \%$ \\
\hline Body-mass index $\left(\mathrm{kg} / \mathrm{m}^{2}\right)$ & $25.8(23.2-28.8)$ & $28.8(25.4-32.9)$ & $<0.001$ & $28.4(25.3-32.0)$ \\
\hline Systolic blood pressure $(\mathrm{mm} \mathrm{Hg})$ & $124(117-136)$ & $127(119-138)$ & $<0.001$ & $134(124-145)$ \\
\hline Diastolic blood pressure ( $\mathrm{mm} \mathrm{Hg}$ ) & $78(70-81)$ & $78(71-83)$ & $<0.001$ & $80(75-87)$ \\
\hline Current Smoker & $275(11 \%)$ & $338(15 \%)$ & $<0.001$ & $16 \%$ \\
\hline $\begin{array}{l}\text { Family history of coronary heart } \\
\text { disease } \S\end{array}$ & $358(14 \%)$ & $297(13 \%)$ & 0.05 & $11 \%$ \\
\hline Metabolic Syndrome & $369(17 \%)$ & $718(36 \%)$ & $<0.001$ & $32 \%$ \\
\hline \multicolumn{5}{|l|}{ Aspirin Use } \\
\hline Any report & $903(35 \%)$ & $784(33 \%)$ & 0.31 & $15 \%$ \\
\hline Prophylactic & $775(30 \%)$ & $678(30 \%)$ & 0.46 & $14 \%$ \\
\hline Total Cholesterol (mg/dL) & $179(163-195)$ & $179(162-194)$ & 0.15 & $185(169-200)$ \\
\hline $\begin{array}{l}\text { Low density lipoprotein } \\
\text { cholesterol (mg/dL) }\end{array}$ & $106(90-118)$ & $106(90-118)$ & 0.82 & $108(94-119)$ \\
\hline $\begin{array}{l}\text { High density lipoprotein } \\
\text { cholesterol (mg/dL) }\end{array}$ & $52(41-65)$ & $48(39-59)$ & $<0.001$ & $49(40-60)$ \\
\hline Triglycerides (mg/dL) & $92(68-133)$ & $105(77-150)$ & $<0.001$ & $118(85-169)$ \\
\hline Glucose (mg/dL) & $91(85-98)$ & $93(87-101)$ & $<0.001$ & $94(88-102)$ \\
\hline $\begin{array}{l}\text { Estimated glomerular filtration } \\
\text { rate }\left(\mathrm{ml} / \mathrm{min} / 1.73 \mathrm{~m}^{2}\right)\end{array}$ & $85(74-98)$ & $85(72-100)$ & 0.17 & $\mathrm{NR}^{\text {II }}$ \\
\hline Framingham Risk Score & $6.4(3.7-10.6)$ & $7.0(4.0-11.9)$ & $<0.001$ & NR \\
\hline Reynolds Risk Score & $6.9(3.6-12.0)$ & $8.9(4.8-7.6)$ & $<0.001$ & NR \\
\hline C-reactive protein $(\mathrm{mg} / \mathrm{L})$ & $0.84(0.49-1.3)$ & $4.4(2.9-7.6)$ & $<0.001$ & $4.3(2.8-7.1)$ \\
\hline \multicolumn{5}{|c|}{ * Values are frequency (percent) or median (interquartile range). } \\
\hline \multicolumn{5}{|c|}{ P value compares REGARDS participants by C-reactive protein group. } \\
\hline \multicolumn{5}{|c|}{ from Ridker et. al. [9] } \\
\hline \multicolumn{5}{|c|}{$\S_{\text {Data were missing for } 102 \text { REGARDS participants. }}$} \\
\hline
\end{tabular}




\section{Table 2}

Relative Risk of Mortality for Elevated C-reactive Protein among those Eligible for Justification of the Use of Statins in Primary Prevention: an Intervention Trial Using Rosuvastatin (JUPITER).

\begin{tabular}{ll}
\hline Model & Relative risk with CRP $\geq \mathbf{2}$ mg/L ${ }^{*}$ \\
\hline Unadjusted & $1.54(1.11,2.14)$ \\
Adjusted for age, sex and race & $1.59(1.15,2.22)$ \\
Adjusted for age, sex, race and risk factors ${ }^{\dagger}$ & $1.49(1.05,2.11)$ \\
Adjusted for age, sex, race, risk factors and metabolic syndrome & $1.53(1.05,2.24)$ \\
\hline$*$ & \\
reference group is those with C-reactive protein $<2$ mg/L. & \\
${ }^{\dagger}$ hypertension, smoking status, education level, body-mass index, cholesterol, HDL, triglyceride and glucose levels, estimated glomerular filtration \\
rate.
\end{tabular}

